\title{
A reality check for students? How participating in the Model United Nations influences skills, IR perceptions and perspectives on future career
}

\author{
Fabrizio Coticchia \\ Enrico Calossi \\ Lorenzo Cicchi
}

\begin{abstract}
The literature has examined in detail the effect of simulations in enhancing students' knowledge or skills. However, despite a growing number of studies on simulations and International Relations (IR), few analyses are based on large samples and most empirical studies still focus on students' views on the simulation itself, rather than investigating how participating in a simulation affects students' perceptions of relevant IR issues. Moreover, almost none of the current analyses on simulations and IR consider how the involvement in a simulation affects students' views on university enrolment or future career. This article seeks to fill these gaps, addressing how students' interpretations and expectations change after participating in the Model United Nations (MUN). How is the MUN perceived as an experience that helps improve personal skills such as language ability, negotiation skills, and knowledge related to IR issues? How and to what extent do perceptions about selected IR issues vary before and after the MUN? How do views on future university enrolment or future work and career vary before and after the MUN? To answer these questions, this article examines original data from a survey submitted to high school and university students participating to two MUNs held in Spring 2018.
\end{abstract}

\section{Keywords}

Simulation, Model United Nations, teaching, skills, perceptions, enrollment

\section{Acknowledgments}

The authors wish to thank all the participants at the panel "New designs for political science teaching" (2018 ECPR General Conference) for their useful comments and suggestions. 


\section{Introduction}

This article falls within the broad literature (Lantis, 1998; Asal, 2005; Blair, 2013; Holland, 2013; Giovanello, et al. 2013; Matt Ryan, et al. 2014; Blair, et al. 2018) investigating the importance of games, simulations and alternative teaching methods in the international relations (IR) field. Among many role-playing experiences, the Model United Nations (MUN) is and one of the most popular IR simulations around the world. It is estimated that 'there are more than 400 conferences annually in 35 countries' and that 'more than 400,000 middle school, high school, and college / university students participate annually worldwide' (Crossley-Frolick, 2010: 186). From a broad perspective, the aim of this work is to analyze how students have modified their own views, interpretations and expectations after participating to the MUN.

This analysis is based on a substantial sample $(\mathrm{N}=218)$, thus addressing one of the shortcomings acknowledged in the literature, i.e. the lack of empirical studies on simulations based on large samples (Giovanello et al, 2013; X and Y 2018). The source of this novel data is a cross-time survey of students participating to two MUNs held in Spring 2018.

More specifically, this article answers the following research questions: how is the MUN perceived as an experience that helps improve personal skills (such as language ability, negotiation skills, and knowledge)? How and to what extent do perceptions vary on selected IR issues before and after the MUN? How and to what extent do views on future university enrollment or future work and career vary before and after the MUN?

The article makes three contributions to the current scholarly debate. First, by examining a rather large empirical sample, it analyzes the evolution of students' perceived skills before and after the simulation, confirming the mainstream view in the literature that affirms the benefits of active learning in IR. Second, the research investigates students' perspectives on selected IR issues (such as conflict and cooperation), corroborating the findings of the very few studies (Youde, 2008; X and Y 2018) that have stressed a (counterintuitive) 'reality check effect' of simulations in tempering the idealism of participants. Finally, it provides a preliminary analysis of how student's viewpoints on future university enrollment or career vary after the simulation.

Furthermore, the study offers three important findings related to the above-mentioned 'reality check'. First, students consider International Organizations (IOs), cooperation, and diplomacy in IR to be highly relevant, but this perceived importance decreases after the MUN. Second, after completing the MUN simulation, participants report that conflict in IR is more important than they had supposed beforehand. Third, their perspectives on future career become less uncertain and more oriented towards curricula that are somehow related to the world of IR.

The article is structured as it follows. After reviewing the current literature debates on the benefits of simulations and MUNs as learning tools, we present the research questions, methodology and data analysis. Three empirical sections then investigate separately: a) the impact of the simulation on skills; b) changes in interpretations over IR, and; c) the influence of MUN on future career assessment. The concluding section discusses the main findings and presents suggestions for further research. 


\section{Are simulations 'useful' teaching methods in IR? Filling the gaps in the literature}

One of the main goals of simulations as a teaching method is to develop students' understanding through practical learning opportunities (Blair et al. 2018). As stated by Lantis, simulations 'have been employed successfully in international relations courses since the late 1950s, but the end of the Cold War has prompted a renewed interest in simulations as interactive teaching tools that capture the dynamics of change in the international system' (1998: 139). Simulations in IR, and other disciplines, aim at 'bringing students into the learning process and engaging their curiosity' (Crossley-Frolick, 2010: 185). Also for this reason, 'the political science community has generally begun to accept that simulations, if used correctly, can be effective tools in the classroom' (Asal and Kratoville, 2013: 132).

The literature ${ }^{1}$ has examined in detail how and to what extent simulations provide benefits to students. Overall, 'a large body of literature has demonstrated the pedagogical value simulations hold for students' (Youde 2008: 349). Despite some criticism of their current usefulness (Raymond, 2010), the vast majority of scholars have affirmed the positive influence of simulations (Ripley et al, 2009; Taylor, 2013) on students' knowledge of IR theories and concepts (Shellman and Turan, 2006), communication skills (Crossley-Frolick, 2010), critical and analytical thinking (Shellman and Turan, 2006), engagement and empowerment (Asal, 2005; Blair et al, 2018), and learning outcomes in comparison with other teaching methods in IR (Frederking, 2005).

Simulations are generally conceived as 'useful' (Holsti, 2000: 259), 'fun' (Crossley-Frolick, 2010: 195), and enjoyable (Shellman and Turan, 2006), representing 'valuable experiences' for students (Lantis, 1998: 150). Youde stresses how 'active learning techniques like in-class simulations offer students a chance to demonstrate their understanding of course material and to explore new issues. They can encourage critical thinking in a fun, less formal manner than a traditional class lecture' (2008: 348). In sum, 'there is a fair amount of pedagogical consensus on the general value of simulation in promotion of knowledge or skill acquisition' (Glasgow, 2014: 526).

Scholarly research ${ }^{2}$ has devoted particular attention to the MUN, one of the most consolidated and popular IR simulations in the world. A MUN basically consists in a simulation of the UN committees where students represent a given country, negotiating with colleagues on draft resolutions. Thus, the MUN requires several skills: from negotiation, communication, research, report writing to the capacity to interact with representatives of other countries and cultures (Ripley et al, 2009). ${ }^{3}$ For these reasons - and because of the variety of issues addressed during the simulation - the MUN is generally viewed as beneficial to students' 'understanding of international relations' (Enterline and Jepsen, 2009: 58) or even superior to conventional classroom methods (Ehralnder and Boylan 2017).

However, despite a growing number of studies on simulations and IR, the current debate still suffers from some gaps and weaknesses. We schematically illustrate three main problems in the literature.

\footnotetext{
${ }^{1}$ For a broad review of the literature on simulations and IR, see, among others: Ripley et al. (2009), Glasgow (2014), Ehralnder and Boylan (2017).

${ }^{2}$ For a review, see; Crossley-Frolick (2010), X and Y (2018).

${ }^{3}$ Because simulations such as the Model United Nations may demand a higher level of preparedness and engagement than the normal classroom setting (Ehralnder and Boylan 2017) several authors (Asal 2005; Crossley-Frolick 2010; X and Y 2018) confirm that advanced preparation and adequate background information beforehand is crucial for the simulation to be conducted effectively.
} 
First, notwithstanding the increasing interest in simulation as a teaching method in IR - and the above-mentioned consensus on the benefits related to role-playing and active learning - few analyses (Giovannello et al, 2013; X and Y 2018; Naude 2018) are based on large samples $(N)$ to empirically assess students' perspectives. In fact, the vast majority of studies that examine the supposed effectiveness of simulations in enhancing learning are generally based on a narrow sample, such as one or two classes, rather than investigating the attitudes of hundreds of students, from high school to universities. ${ }^{4}$

Second, most empirical studies mainly focus on the students' views on the simulation itself, looking at the features they have appreciated more or at the overall perceived usefulness of the active learning exercise. However, few analyses (Asal, 2005; X and Y, 2018) have examined how participating in a simulation such as the MUN affects students' levels of (factual and self-evaluated ${ }^{5}$ ) knowledge and students' perceptions of relevant IR issues (e.g., the primacy of conflict or cooperation in world politics, the different role played by domestic and international factors in influencing foreign policy decisions, etc.).

Third, research that investigates how and to what extent the involvement in a simulation affect students' views on enrolment (for high schools) or future work and career (for universities) has not yet been properly carried out. One of the few studies on the topic affirms that 'who had previously expressed an interest in working in conflict resolution after graduation announced that they had abandoned that goal' Youde 2008: 355-356).

The three above-mentioned gaps in the literature will be addressed in the following sections.

\section{Data, research design and methods}

The data employed in this article comes from a survey submitted to high schools and university students who in 2018 participated the National Model United Nations-New York (NMUN-NY) and the Model United Nations-Rome (MUN-Rome). This survey, prepared by the authors, examines students' attitudes towards the simulation as a learning method and their perceived skills and, before and after the simulation, their viewpoints on selected IR topics and their views concerning future university enrollment or future career.

In line with the above-mentioned literature on the 'benefits of simulations' (Lantis, 1998; Holsti, 2000; Shellman and Turan, 2006; Taylor, 2013), we expect that students will positively assess the whole experience, while their self-perceptions on knowledge, communication and negotiation skills will increase after the MUN simulations. Moreover, as a preliminary analysis, we also assume that, due to the deep involvement within an international environment, constantly addressing issues connected to world politics and diplomacy, students will enhance their aspirations concerning jobs/universities/courses related to IR, Political Science and IOs. In other words, we guess that the concrete day-by-day engagement in a 'believable, reality-based situation' (Asal and Kratoville, 2013: 133), 'within which students can experience the application of abstract theories of international

\footnotetext{
${ }^{4}$ It is also worth noting that few analyses consider, both high school and university students at the same time.

5 'Self-evaluated knowledge' can be conceived as part of the broader concept of 'metacognitive knowledge' (Krathwohl 2002), or the knowledge of one's own cognition. According to X and Y (2018), self-evaluated knowledge consists of the self-assessment of the participants' knowledge, regarding IR issues.
} 
relations and foreign policy to tangible policy problems' (Enterline and Jepsen, 2009: 50) will foster their passion and interest towards these subjects.

Finally, and above all, this article verifies and develops the findings of the (still limited) research on students' perceptions of IR issues and concepts. Relatedly, two different viewpoints can be highlighted by examining this literature. First, one could reasonably expect that because simulations 'enable participants to work collaboratively and creatively in purposeful situations' (Kempston and Thomas, 2015: 460), and participants work 'collaboratively together (...) to further promote the spirit of dialogue' (Hatipoglu et al, 2014: 401) to reach an agreement from different points of views and interests, students will attribute greater relevance to cooperation rather than to conflict. It would also be reasonable to think they will devote more importance to diplomatic and institutional tools rather than military ones. Second, and conversely, we would assume students' idealism about IR might be tempered by active learning activities since simulations put learning into practice, revealing the complexities of the international system, as well as the 'difficulties associated with negotiation, coalition formation, and diplomacy' (Crossley-Frolick, 2010: 196). This is the main finding of Youde, who concludes that simulations 'offer a unique venue for exploring the tensions between theory and practice, forcing students to consider their own idealism' (2008: 355), and highlights how difficult it is to put ideals into practice. Indeed, 'with simulations, students confront how the rules of diplomacy and the unequal distribution of power among state and non-state actors complicate coordinated responses to problems spanning across national borders' (Crossley-Frolick, 2010: 185). In their recent study, $\mathrm{X}$ and Y (2018) find, surprisingly, that the perceived relevance attributed by students to 'conflict' increases over time, even if it continues to be considered by students as less important than 'cooperation'. According to the authors, the attention devoted by the training course to the features of the assigned country before the simulation may have encouraged students to focus primarily on national interests and goals, rather than cooperation and dialogue. But, as affirmed by Youde (2008), at the end of the simulation students were not completely disillusioned ${ }^{6}$ but simply better understood the complexity of negotiation. In other words, simulation may represent a 'reality check' for students' idealism. Thus, in line with this view, one could expect an increase (rather than a decrease) in the relevance attributed by students to the issue of conflict (over cooperation). This article contributes to the current debate also by empirically assessing these two different perspectives.

Using a similar methodology to previous surveys adopted to assess students' attitudes towards simulations (Shellman and Turan, 2006; X and Y, 2018), we submitted the online questionnaire to all students $^{7}$ before the beginning of the preparatory course (T1), and after the MUN actual simulations (T2). In particular, we investigated those participants that had previously attended a training course. In our case, this preparatory course was provided by a non-profit organization, anonymized under the letter ' $\mathrm{X}$ ' for the purpose of this article. The preparation consists of 100 hours of face-to-face lessons and practical exercises. The content of the classes covers the topics of International Relations, Resolution and Report Drafting, Speech and Public Speaking, and Procedural Rules. The overriding principle of the whole course is to 'stay in character'-designed to ensure students approach negotiations based on their assigned country's strategic interests and diplomatic culture rather than

\footnotetext{
${ }^{6}$ This is empirically confirmed also by $\mathrm{X}$ and Y (2018), who find that the overall value of cooperation remains higher than that of conflict also after the simulation.

${ }^{7}$ Approximately 500 students coming from Italian high schools and universities.
} 
their own. ${ }^{8}$ All these students also participated to a 'smaller MUN' (structured only on a few UN committees) organized by Organization X in Rome some days before the NMUN in New York, ${ }^{9}$ in order to practice and test the skills and knowledge acquired during the training course. Not all the students actually attended the NMUN in New York; for them, the MUN in Rome represented in itself the conclusion of the whole project. Table 1 presents the data disaggregated by gender, level of education, and the kind of final stage of their project (NMUN New York or MUN Rome).

Table 1: Sample distribution

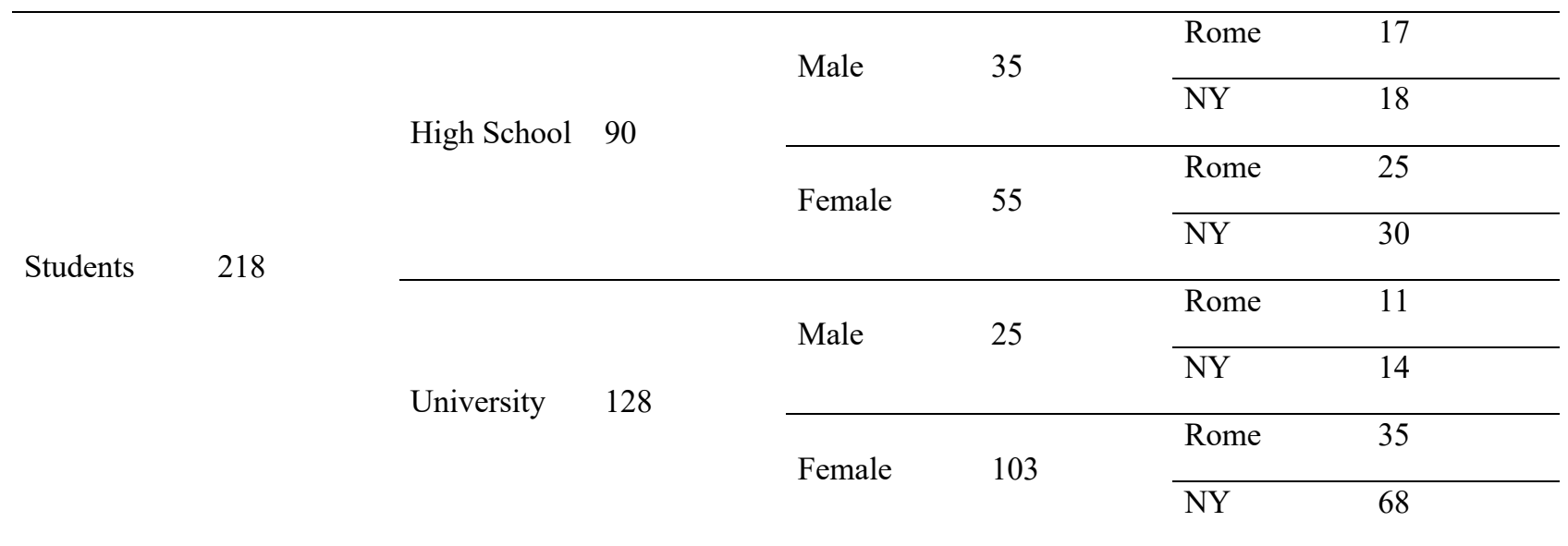

Source: authors' own compilation. ${ }^{10}$

Basing our analysis on this original dataset, we can test a series of hypotheses that aim at answering the following research questions:

1) How is the MUN perceived as an experience that helps improve personal skills (such as language ability, negotiation skills, and general knowledge)?

2) How and to what extent do perceptions vary on selected IR issues before and after the MUN?

3) How and to what extent do views on future university enrollment or future work and career vary before and after the MUN?

As far as the specific hypotheses on the simulations and students' perspectives are concerned, three are related to the first research question:

H1: Students perceive their skills (general knowledge, language ability, negotiation rules) as improved after the simulation.

We expect that different groups of students, with differing levels of prior exposure to the relevant

\footnotetext{
${ }^{8}$ For instance, the preparatory course provides specific lectures on the politics, economy, institutions, foreign policy, history, etc. of the assigned country. Furthermore, students are invited to meet the actual country's diplomats based in New York.

${ }^{9}$ The National Model United Nations in New York (NMUN-NY) is organized annually and managed by the National Collegiate Conference Association (NCCA). Around 5,000 students from the all over the world attend the conference in New York. For details on students' nationalities and school origins, see http://www.nmun.org/about-nmun/mission-andhistory.html.

${ }^{10}$ The average age our sample was 22 years for university students and 17.1 years for high school students.
} 
themes and training, will report varying levels of perceived skills improvement. In particular, we expect that a higher increase among high school students than for university students. Indeed, as illustrated above, the gap between the overall active experience of the MUN (which includes also the training course) and the traditional classes participants attend is somewhat greater for high school students, who are less frequently involved in active learning, simulations, or role-playing. Moreover, we also expect that those students who attended the complete program (i.e. participating in the NMUN-NY rather than concluding the experience at the Rome simulation) would benefit from further and more complex activities, thus receiving higher skills. Therefore, the following two subhypotheses are developed:

Hla: The perceived improvement in skills (general knowledge, language ability, negotiation rules) is greater for high school students than for university students.

H1b: The perceived improvement in skills (general knowledge, language ability, negotiation rules) is greater for students attending the NMUN-NY than for students concluding their experience with the MUN Rome.

Two other (alternative) hypotheses are related to the second research question, and register the interpretations of literature on MUN's influence over students' perception of IR issues. ${ }^{11}$ The first considers MUN participation as strongly beneficial to 'promote the spirit of dialogue' (Hatipoglu et al, 2014: 401) and all those elements linked to it (such as cooperation vs conflict, use of diplomatic means vs. military ones, role of IOs, etc.), which are expected to increase their importance in students' perceptions. On the contrary, in line with the alternative hypothesis (Youde, 2008; X and Y, 2018), the actual dynamics of the MUN limits the optimistic expectations of students. Thus, such a 'reality check' would cause an increase in the perceived salience of conflict (and defense of national interests, etc.) over cooperation (diplomacy, multilateral institutions, etc.). Therefore, the opposing hypotheses are as follows:

H2a: All those features of IR that are related to cooperation amongst countries are considered crucial and their importance increases during the simulation.

$H 2 b:$ All those features of IR that are related to cooperation amongst countries are considered crucial, but their relative importance decreases during the simulation.

The final hypothesis refers to the third research question and is linked to the strategies of future career (of studying and/or working) of students. Obviously, we expect the students' interest in IR to be high already before the simulation and that professions and curricula linked to international politics are considered very attractive. However, we also expect that these preferences would be reinforced during the MUN participation. Therefore:

H3: Aspirations to enroll in university courses or pursue professions related to IR or Diplomacy increase after attendance at the MUN.

These hypotheses are discussed in the next empirical sections.

\footnotetext{
${ }^{11}$ Rather than tracing the causal relationship between the participation in MUNs and the change in students' perceptions and skills, the aim of this analysis is to highlight the co-evolution among the above-mentioned factors and the simulation.
} 


\section{The influence of the Model United Nations on students' skills}

As we have already discussed in the previous sections, there is a general consensus in the literature that sees participation in simulations as beneficial to students' skills. In our survey, we tried to unpack those skills by identifying at least three different components: general knowledge, negotiation ability, and language. When students join a MUN, they often become 'delegates' of countries they are not familiar with or no little about. Therefore, students are coached during the training course to learn the history, the internal political and economic determinants, foreign policy and strategic doctrine of that (almost unknown) country, whose national interests they are charged to defend. In addition, students must also study the history and functioning of the most important IOs and the foreign policy the great powers and neighboring states have towards their country, in order to distinguish friend from foe. Overall, even before participating in the simulation proper, the student has received a huge amount of updated information, which is added to during the MUN itself.

Another target students are required to achieve is the development of public speaking and negotiation skills in English. Most students in our sample are not English native speakers and/or are not used to speaking in public. These, then, are new skills we expect students to improve during the simulation. The third component is represented by a very specific item: 'negotiation skills'. Already during the training course, students are familiarized with two specific topics, i.e. 'Resolution and Report Drafting' and 'Procedural Rules'. Both represent a subject of study very seldom (if ever) addressed during regular university and high school activities. In this case, we also expect an increase in perceived knowledge after the simulation. In the questionnaire, students are required to evaluate their skills by answering whether 'the MUN has increased their knowledge/negotiation skills/language ability'. The possible answers are represented by a classical 1 to 5 scale, where 1 stands for 'Fully disagree', 2 for 'Disagree', 3 for 'Neither disagree/Neither agree', 4 for 'Agree', and 5 for 'Fully agree'. Therefore, results higher than 3 capture a positive evaluation of the program on these aspects. Table 2 shows students' evaluation of the MUN's influence on their skills, with the sample divided by gender, level of education, and involvement in the NY or Rome programs.

Table 2: Skills

\begin{tabular}{lcccccccccc} 
& \multicolumn{3}{c}{ Gender } & \multicolumn{3}{c}{ Education } & \multicolumn{3}{c}{ Program } \\
& $\mathrm{M}$ & $\mathrm{F}$ & $\Delta$ & H.S. & Univ. & $\Delta$ & Rome & $\mathrm{NY}$ & $\Delta$ & Overall \\
\hline Knowledge & 4.20 & 4.37 & +0.17 & 4.35 & 4.24 & -0.13 & 4,21 & 4,32 & +0.11 & 4.28 \\
Negotiation & 3.78 & 3.81 & +0.03 & 3.81 & 3.75 & -0.06 & 3,78 & 3,77 & -0.02 & 3.77 \\
Language & 4.05 & 3.91 & $-0,14$ & 3.99 & 3.85 & -0.14 & 3,76 & 3,98 & +0.22 & 3.90 \\
\hline
\end{tabular}

Source: authors' own compilation.

Overall, students confirm that the MUN has positively contributed to improving their skills (all values are higher than 3). In detail, students consider 'general knowledge' as having been boosted the most, much more than negotiation and language skills, which both score similarly. Therefore, $H I$ is fully confirmed, in the sense that students consider the MUN experience as 'increasing' (and in the case of knowledge almost 'fully increasing') their personal skills. 
Unpacking the sample by students' level of education, we can compare the evaluations of the high school students and those at university. For all three analyzed skills, we note that both the categories of students consider general knowledge to be the skill most improved by the MUN experience, followed by language abilities and, finally, negotiation skills. But, more importantly for the present research, we note that high school students recount a greater boost to personal skills than that reported by their university colleagues. This was expected by our Hla, which is therefore fully confirmed. As experienced teachers ${ }^{12}$ of the preparatory course for Organization $\mathrm{X}$, we are aware that simulations are seldom, if ever, used as a teaching tool in high schools. This was confirmed in our informal conversations with students during the MUN simulations. And this can have a positive impact on high school students' perception in evaluating MUN's influence on their negotiation and language skills. Moreover, the general knowledge of current international events and country profiles of an average high school student is much lower than that of a university student. This also explains the variation (indicated with the Greek letter delta, $\Delta$ ) in knowledge.

As for $H 1 b$, we differentiate the students attending the NY simulation from those attending the Rome MUN. We expect the former to report greater improvements in all three analyzed skills. The reason is that participation at the NMUN New York represents a further experience for students, who, as said, all attended the training course and the Rome simulation. Actually, this happens only for knowledge and language, while for the negotiation skills the two sub-groups express almost the same evaluation. Stated differently, the NMUN New York seems to give students an 'added value' on knowledge and language ability, while for negotiation skills it does not seem to make any difference with respect to the simple participation in the MUN Rome. Therefore, $H 1 b$ is only partially confirmed. Nonetheless, full confirmation of $H 1$ and $H 1 a$ demonstrate the importance of the MUN as a learning activity.

This is also confirmed by the results of at least other three questions we included in our survey. After the end of the program, we asked the students whether they consider the participation in the MUN as 1. A useful experience and 2. A fun experience. Moreover, we also asked them 3 . Whether they would suggest such an experience to other students. As with the questions on skills change, students were asked to assign a score on a five-point scale to these questions: 1 means 'fully disagree' that participation at the MUN was useful or fun and would be recommended to other students; 5 means 'fully agree' with those statements. Table 3 presents this additional information.

Table 3: Is the MUN useful, fun and would you recommend it to others?

\begin{tabular}{lcccccccccc} 
& \multicolumn{3}{c}{ Gender } & \multicolumn{3}{c}{ Education } & \multicolumn{3}{c}{ Program } \\
& $\mathrm{M}$ & $\mathrm{F}$ & $\Delta$ & H.S. & Univ. & $\Delta$ & Rome & $\mathrm{NY}$ & $\Delta$ & Overall \\
\hline Useful & 4.43 & 4.37 & -0.06 & 4.45 & 4.27 & -0.18 & 4.31 & 4.35 & +0.05 & 4.33 \\
Fun & 4.37 & 4.23 & -0.14 & 4.28 & 4.26 & -0.02 & 4.07 & 4.38 & +0.31 & 4.27 \\
\multirow{2}{*}{ Recommend } & 4.48 & 4.29 & -0.19 & 4.43 & 4.23 & -0.20 & 4.21 & 4.36 & +0.15 & 4.30 \\
\hline
\end{tabular}

Source: authors' own compilation.

\footnotetext{
${ }^{12}$ All three authors, in fact, have taught IR classes at various Italian universities, on behalf of Organization X, in recent years.
} 
In general, students offered strong positive feedback on the project, as it is demonstrated by the high scores received for the statements 'the MUN is a useful/fun experience' and 'I would recommend it to other students'. As for the usefulness of the experience, there is limited variation by gender and program, while, according to the level of education, high school students considered the program more useful than university students. The reason might be found again in the 'exceptional' nature of such a simulation in the eyes of high school students.

Regarding the enjoyment value of the experience, in line with previous research (Crossley-Frolick, 2010), there is a similar positive judgment by high school and university students, while men are inclined to consider the experience funnier than what female declare. But more important is the variance between the NY and the Rome participants, with the former considering the experience much more fun than students attending the Rome program only.

To conclude, the propensity to recommend participation to other students is the element that registers the highest levels of variance. In fact, although all the unpacked sub-groups would recommend MUN participation to other students, this propensity varies significantly. In detail, males (compared to females), high school students (compared to university students) and the NY participants (compared to Rome participants) are the sub-groups that declare the highest propensity to recommend the experience to others. These sub-groups, quite logically, are also those that consider the experience more fun and more useful.

\section{The influence of the Model United Nations on students' perception of IR issues}

Despite the vast majority of analyses on role-playing, active learning, and IR mainly collect the student's views on the simulation itself, this article is in line with the (rare) existing studies (Asal, 2005; X and Y, 2018) that examine how the involvement in a simulation influences students' perceptions of selected relevant IR issues. Four main subjects have been addressed specifically.

First of all, we assess the perceived relevance of cooperation and conflict in IR. Students answer the question: 'in your opinion, are international relations characterized more by cooperation or by conflict?'. Respondents may attribute a score from 1 (IR are characterized 'only by cooperation') to 5 (IR are marked 'only by conflict'). This question, as well as the following ones, allows the two above-mentioned different perspectives on how the MUN affects students' view on IR to be confronted. As stated, because the exercise is structured around dialogue and the exchange of information within a multilateral institution — and because reaching agreement is the main goal-one might assume that students' sense of the salience of cooperation in IR might increase after the simulation. On the other side, active learning might be expected to introduce a 'reality check' on the idealism ${ }^{13}$ of participants, who are led to understand how complex it is to negotiate and whose attention (especially in the training courses before the simulation) is expressly focused on the national interests of the states they represent (rather than on cooperation within multilateral institutions). Empirical findings (see Table 4) confirm the previous results by X and Y (2018), stressing how

\footnotetext{
13 'Idealism' is here conceived not as a commitment to 'utopia' but rather as a synonym of the IR paradigm thatdifferently from realism - mainly focuses on diplomacy and cooperation in IR.
} 
students consider 'cooperation' as more important than 'conflict' overall, but still report an increased salience for 'conflict' after the simulation (the scores move from 2.66 in T1 to 2.72 in T2). These results confirm the validity of $H 2 b$ over the opposing hypotheses $H 2 a$. Our analysis indeed clearly shows that those features of IR that concern cooperation among countries are considered more relevant, but their relative importance decreases during the simulation.

Table 4: Cooperation and Conflict

\begin{tabular}{lcccccccccc} 
& \multicolumn{3}{c}{ Gender } & \multicolumn{3}{c}{ Education } & \multicolumn{3}{c}{ Program } \\
& $\mathrm{M}$ & $\mathrm{F}$ & $\Delta$ & H.S. & Univ. & $\Delta$ & Rome & $\mathrm{NY}$ & $\Delta$ & Overall \\
\hline Coop-confl T1 & 2.62 & 2.68 & +0.06 & 2.64 & 2.67 & +0.03 & 2.61 & 2.69 & +0.08 & 2.66 \\
Coop-confl T2 & 2.55 & 2.78 & +0.23 & 2.74 & 2.70 & -0.04 & 2.65 & 2.77 & +0.12 & 2.72 \\
Coop-confl T2-T1 & -0.07 & +0.11 & & +0.10 & +0.03 & & +0.03 & +0.08 & & +0.06 \\
\hline
\end{tabular}

Source: authors' own compilation.

Disaggregating the data, it is worth noting how $H 2 b$ is fully confirmed by women (with a shift from 2.68 to 2.78), while for men - who in any case represent the minority of the sample - the figures are dissimilar (indeed, for them the weight of cooperation actually increases). On the contrary, there are no significant differences in the scores between university/high school students or between the type of program attended (in both cases the importance of 'conflict' increases, especially for the latter cases).

The second subject also supports the argument that MUN is a 'reality check' experience. The survey asked which kind of foreign policy tools_-'diplomacy and cooperation' or 'security and military' the state should adopt to address challenges such as terrorism and migration flows. ${ }^{14}$

As illustrated by the most recent Eurobarometers (2016, 2017, 2018), the two issues represent the 'top concerns' ${ }^{15}$ nominated within European public opinion in recent years. Both challenges, despite their clear differences, can be tackled by diplomatic and/or military means. Table 5 illustrates the results, revealing that while the scores related to the best way to address terrorism remain stable across time (confirming the importance of cooperation and diplomacy), the perceived relevance of military tools for migration increases from T1 (2.05) to T2 (2.24). Here, some differences in the scores related to gender are observed, being women more inclined towards diplomacy and cooperation, even if that diplomatic preference is reduced after the simulation.

\footnotetext{
${ }^{14}$ Students may attribute a score from 1 ('Only diplomatic tools') to 5 (Only military and security instruments').

15 See European Commission, Press Release, 14 June 2018, available at: http://europa.eu/rapid/press-release_IP-184148 en.pdf.
} 
Table 5: Diplomatic or Military Tools?

Gender

Education

Program

\begin{tabular}{lcccccccccc} 
& $\mathrm{M}$ & $\mathrm{F}$ & $\Delta$ & H.S. & Univ. & $\Delta$ & Rome & $\mathrm{NY}$ & $\Delta$ & Overall \\
\hline Terrorism T1 & 3.10 & 2.54 & -0.56 & 2.86 & 2.58 & -0.28 & 2.76 & 2.65 & -0.11 & 2.69 \\
Migration T1 & 2.25 & 1.97 & -0.28 & 2.08 & 2.03 & -0.05 & 2.03 & 2.06 & +0.03 & 2.05 \\
\hline Terrorism T2 & 2.82 & 2.60 & -0.22 & 2.83 & 2.54 & -0.29 & 2.66 & 2.66 & 0.0 & 2.66 \\
Migration T2 & 2.43 & 2.16 & -0.27 & 2.30 & 2.20 & -0.10 & 2.22 & 2.25 & +0.03 & 2.24 \\
\hline Terrorism T2-T1 & -0.28 & +0.06 & & -0.02 & -0.04 & & -0.10 & +0.02 & & -0.03 \\
Migration T2-T1 & +0.18 & +0.19 & & 0.22 & +0.16 & & +0.18 & +0.19 & & +0.19 \\
\hline
\end{tabular}

Source: authors' own compilation.

Note the figure related to 'migration'. Although the overall number highlights the prominence of 'cooperation and diplomacy' as the best tools to address the challenge, after the simulation we observe a (small but still noteworthy) shift towards according greater importance to military instruments. In other words, after having attended the simulation, shared information with colleagues, and negotiated within a multilateral framework, the participants still believe in cooperation and diplomacy as a crucial asset to solve challenges such as migration, but less so than before.

The third subject, however, is indeed the one that most clearly shows the importance of MUN as an experience that tempers students' idealism concerning IR. Table 6 below presents the results of the question 'How much importance do you think International Organizations such as the United Nations are in facing today's great challenges?'.

Table 6: Importance of International Organizations

Gender

Education

Program

\begin{tabular}{lcccccccccc} 
& $\mathrm{M}$ & $\mathrm{F}$ & $\Delta$ & H.S. & Univ. & $\Delta$ & Rome & $\mathrm{NY}$ & $\Delta$ & Overall \\
\hline IO importance T1 & 4.02 & 4.49 & +0.47 & 4.54 & 4.23 & -0.32 & 4.35 & 4.36 & +0.01 & 4.36 \\
IO importance T2 & 3.67 & 4.24 & +0.57 & 4.16 & 4.03 & -0.12 & 4.13 & 4.05 & -0.07 & 4.08 \\
IO importance T2-T1 & -0.35 & -0.25 & & -0.39 & -0.20 & & -0.23 & -0.31 & & -0.28
\end{tabular}

Source: authors' own compilation.

The results indicate that students start this experience with an extremely high opinion of IOs (overall, 4.36 on a scale between 1 and 5). At T2, this perception has decreased systematically among all subgroups. That said, despite the substantial decrease ( 0.28 overall), the value remains quite high. In other words, this simulation experience appears to have produced a 'reality check' moderating students' idealism concerning the world of IR. Thus, $H 2 b$ appears to be fully confirmed. 
Fourth, in line with previous analyses that investigated student's perceptions of both domestic and international factors and foreign policy (Enterline and Jepsen, 2009; X and Y, 2018), we ask in three different questions how important they think it is that the state spend money for 'welfare (health, jobs, etc.)', 'defense and security (armed forces, intelligence, etc.)', or 'foreign policy (diplomacy, cooperation, etc.)'. Students give scores from 1 ('not important at all') to 5 ('very important') for each issue. One might expect that, after the MUN, the relevance attributed to diplomacy by the whole exercise would see commitments to 'foreign policy' spending increase. On the contrary (see Table 7), the perceived value of 'foreign policy' expenditures remains stable, while that for 'defense' rises slightly. Commitment to public spending on 'welfare' also falls slightly, but students still accord it the greatest significance overall. This appears more in line with the 'reality check' argument, which also stresses how students spend a lot of time in examining the (domestic) features of the country they represent as well as the 'defense' of its interests. And this aspect may help to explain the results in the previous table (5) on the decreased perceived relevance of IOs.

Table 7: Public Expenses

\begin{tabular}{|c|c|c|c|c|c|c|c|c|c|c|}
\hline & \multicolumn{3}{|c|}{ Gender } & \multicolumn{3}{|c|}{ Education } & \multicolumn{4}{|c|}{ Program } \\
\hline & M & $\mathrm{F}$ & $\Delta$ & H.S. & Univ. & $\Delta$ & Rome & NY & $\Delta$ & Overall \\
\hline Welfare T1 & 4.48 & 4.63 & +0.15 & 4.57 & 4.60 & +0.03 & 4.57 & 4.60 & 0.03 & 4.59 \\
\hline Foreign Policy T1 & 4.03 & 4.21 & +0.18 & 4.01 & 4.27 & +0.26 & 4.06 & 4.23 & +0.17 & 4.16 \\
\hline Defense $\mathrm{T} 1$ & 3.40 & 3.79 & +0.39 & 3.66 & 3.70 & +0.04 & 3.72 & 3.66 & -0.06 & 3.68 \\
\hline Welfare T2 & 4.45 & 4.58 & +0.13 & 4.52 & 4.55 & +0.03 & 4.49 & 4.58 & +0.09 & 4.54 \\
\hline Foreign Policy T2 & 3.98 & 4.19 & +0.21 & 4.00 & 4.23 & +0.23 & 4.09 & 4.16 & +0.17 & 4.13 \\
\hline Defense T2 & 3.68 & 3.75 & +0.07 & 3.83 & 3.66 & -0.17 & 3.82 & 3.68 & -0.14 & 3.73 \\
\hline Welfare T2-T1 & -0.03 & -0.05 & & -0.04 & -0.05 & & -0.08 & -0.02 & & -0.05 \\
\hline Foreign Policy T2-T1 & -0.05 & -0.02 & & -0.01 & -0.04 & & +0.03 & -0.07 & & -0.03 \\
\hline Defense T2-T1 & +0.28 & -0.04 & & +0.18 & -0.04 & & $+0,10$ & +0.02 & & +0.05 \\
\hline
\end{tabular}

Source: authors' own compilation.

\section{The impact of the Model United Nations on students' future career}

The aim of this section is to preliminarily investigate how, and to what extent, MUN participation influences students' views on future studies or future career choices. Few authors have investigated this, apart from the already mentioned Youde (2018). Our hypothesis is rather 'optimistic', even if the previous two sections have illustrated the role of the MUN as a 'reality check'.

Therefore, according to $H 3$, we expect that students' propensity to aspire to professions and curricula linked to international politics is already high before the simulation, but that it would further increase after the end of the project. 
To test this hypothesis, we asked students to indicate their plans for future university studies (only for high school students), for studies after the current degree (only for university students), and for their future desired professions (for all the students). Obviously, we include the same questions in both the questionnaires at $\mathrm{T}_{1}$ and $\mathrm{T}_{2}$. Table 8 shows us the high school students' aspirations regarding future university careers.

Table 8: Which kind of university program do you want to enroll in?

\begin{tabular}{llll} 
& T1 N & T2 N & $\Delta$ \\
\hline Economics & 11 & 11 & \\
Technical-scientific & 16 & 16 & \\
Law & 9 & 9 & +2 \\
Languages & 3 & 5 & +3 \\
Political Science & 6 & 9 & -6 \\
I still don't know & 33 & 27 & +1 \\
Other & 12 & 13 & \\
$N$ & 90 & 90 &
\end{tabular}

This data refers to high school students only. Source: authors' own compilation.

At T1 we notice that slightly more than one third of high school students declare not having any clear idea for the future. The 'technical-scientific' curricula (such as engineering, medicine etc.) and 'economics' are those that receive the highest interest. After the simulation, the percentage of the uncertain drops and the preferences towards 'languages' and 'political science' curricula increase. Although the number of the respondents to this question is limited, this tendency confirms our hypothesis (the tilt towards IR-related curricula, like those of languages and political science, increases) and also the overall trend of the 'reality check', which seems be to a latent and important by-product of participating in the MUN. ${ }^{16}$

Corresponding to what we have shown for high school students, Table 9 offers insights about the expectations for future studies among university students.

\footnotetext{
${ }^{16}$ A larger $\mathrm{N}$ would have strengthened the significance of our findings on enrolment. However, these results are important as our research represents one of the first attempts to investigate an understudied issue in the literature.
} 
Table 9: Will you continue studying after your current degree?

\begin{tabular}{llll} 
& T1 N & T2 N & $\Delta$ \\
\hline No & 9 & 4 & -5 \\
Yes, in communication and marketing & 4 & 5 & +1 \\
Yes, in diplomacy and cooperation & 53 & 53 & - \\
Yes, in economics & 8 & 12 & +4 \\
Yes, in a technical-scientific field & 2 & 1 & -1 \\
Yes, but I still don't know in which area & 37 & 35 & -2 \\
Yes, in another area & 15 & 18 & +3 \\
$N$ & 128 & 128 & \\
\hline
\end{tabular}

This data refers to university students only. Source: authors' own compilation.

At T1 41\% of students declare an interest in continuing studies in diplomacy and cooperation. The IR-orientation of the university students was already very clear before the simulation. On the contrary, at T1 $36 \%$ of students do not want to continue studying or do not have any idea about it. The other students are distributed among communication and marketing, economics, a technical-scientific area or in non-specified disciplines. At T2 the levels of uncertainty have decreased substantially. In fact, the number of students oriented toward no further study shifts dramatically (down by half), while the share who are uncertain about which area they will pursue in continuing studies decreases slightly. Overall, after the simulation only $30 \%$ of students plans to drop university or are uncertain about their future career. Although those students who have changed their mind do not seem to add themselves to those inclined towards diplomacy and cooperation (the figure remains perfectly stable between T1 and T2), the MUN seems to have performed its formative mandate to reduce the level of future career uncertainty.

After having discussed the influence of the MUN on the future university career of participants, the next table shows the MUN's influence on the professional aspirations of students. 
Table 10: What will be your future profession?

\begin{tabular}{llll} 
& T1 N & T2 N & $\Delta$ \\
\hline Commerce & 2 & 0 & -2 \\
Development cooperation & 15 & 14 & -1 \\
Diplomatic corps & 19 & 24 & +5 \\
Journalism & 10 & 11 & +1 \\
Civil servant & 5 & 3 & -2 \\
Entrepreneurship & 9 & 11 & +2 \\
Private practice & 22 & 16 & -6 \\
Marketing and communication & 14 & 19 & +5 \\
International Organizations & 59 & 51 & -8 \\
Politics & 4 & 4 & -1 \\
Artistic and musical sector & 4 & 3 & - \\
Private sector as employee & 1 & 1 & +5 \\
European Union & 6 & 11 & -3 \\
University and research & 11 & 8 & -1 \\
I still don't know & 31 & 30 & +6 \\
Other & 6 & 12 & \\
$N$ & 218 & 218 & - \\
\hline
\end{tabular}

These data refer to both high school and university students. Source: authors'own compilation.

Before the simulation $27.1 \%$ of students wanted to work for an IO, $8.7 \%$ in the diplomatic corps, $6.9 \%$ in development cooperation, and $2.8 \%$ for the European Union. Overall, $45.5 \%$ of students want to work in a profession linked to the international environment. In contrast, $14.2 \%$ of students reported no clear or preferred idea for their future.

After the simulation things changed in a way that needs further explanation. First, the number of 'uncertain students' remains stable. In this sense, the MUN seems not having reduced the level of uncertainty. Concerning the professions, the number of those willing to work for a general IO drops, surprisingly, while the share aspiring to join the diplomatic corps or EU institutions increases (the number oriented towards development cooperation remains virtually the same). In total, $45.8 \%$ of students indicate a profession linked to IR as their preferred choice. This figure is almost the same as before the MUN.

However, if the topline figures remain the same, the characteristics of the IR-related professions nominated as a preference shifts. The number stating an aspiration to work for a general 'international organizations' falls, while the share nominating a more specific IR profession, such as joining the diplomatic corps or the European Union, increases. Therefore, here as well we see a distinct impact on levels of professional uncertainty (a shift in preference from the general to the particular). But 
there is also another explanation, which is linked to the fact that students during the simulation, even though placed within an international organization (in the specific the UN committees), do not work as UN officials but as diplomatic representatives of a country (and in some case as representatives of EU member states). Therefore, the simulation teaches students to work as diplomatic representatives rather than generic representatives of some 'international organizations'.

To conclude, we can affirm that our hypothesis is fully confirmed concerning future enrollment plans for university studies. In that case, although students are already generally oriented towards IR courses (or similar studies), this tendency is reinforced by MUN participation. In addition, MUN participation reduces the number of students uncertain about their future university career. Regarding the professions, although we see no fall in the share of students with no clear idea for their future profession, however, among those already oriented towards a profession linked to international politics, there is again a 'reality check'. In fact, those students change their preferences towards even more focused and specific professions (i.e. diplomatic officer or EU official) instead of continuing to nominate the generic and undetermined 'international organizations'.

\section{Conclusions}

Our study, based on an original dataset with a larger $\mathrm{N}$ than most existing studies, sheds some additional light on a type of learning tool, the Model United Nations, that has become more and more prevalent in universities around the world. Kempston and Thomas (2015) have explored the 'pedagogical utility' of the simulation as a teaching tool, revealing how it offers a 'mechanism for a deeper appreciation of regional politics and crises' (2014: 470). Indeed, as stated by Winham, 'there are some aspects of negotiations that students are not likely to understand fully until they have lived through them'" (2002: 465). In other words, 'simulations allow better understanding of the complexities of summit diplomacy and global problem solving’ (Lantis, 1998: 150).

In line with these conclusions, the findings of our analysis reveal that involvement in the MUN simulation represents a 'reality check' for students' idealism. In fact, with little systematic variance between subgroups (high school/university, Rome/New York, but somewhat more variance by gender), students who attend MUNs tend to view IOs with less idealism, according them importance but not as much as before the experience (Youde: 2008). More specifically, they tend to conceive conflict in IR as more salient than they had thought it was before the MUNs-and, vice versa, they see cooperation in IR as less important than they had assumed it to be beforehand ( $\mathrm{X}$ and Y, 2018). In addition to this, after the MUN students are less doubtful about their future university and career aspirations, and more willing to enroll in curricula that are consistent with an international experience, such as the MUN. All in all, these elements underscore the conclusion that simulations are a valid and enriching experience for both high school and university students.

Further research could try to confirm and generalize our findings with even larger samples, especially concerning our preliminary analysis of the influence of simulations on student's views about future studies and career. For instance, a comparative study might confront different national samples emphasizing recurrent patterns, regularities and differences, and their main drivers. Moreover, further studies could test our hypotheses through an experimental design, i.e., submitting the same survey to students not participating in a simulation and learning through seminars and reading only. In addition, a more in-depth analysis correlating students' perceptions about specific issues to particular 
background information (such as language, age, or experience studying abroad) could lead to meaningful results. Finally, a more detailed gender-based approach could also represent a fruitful avenue for further research. 


\section{References}

Asal V (2005) Playing games with international relations. International Studies Perspectives 6(3): $359-373$.

Asal V and Kratoville J (2013) Constructing International Relations Simulations: Examining the Pedagogy of IR Simulations Through a Constructivist Learning Theory Lens. Journal of Political Science Education 9(2): 132-143.

Blair A (2013) Democratising the Learning Process: The Use of Twitter in the Teaching of Politics and International Relations. Politics. 33(2): 135-145.

Blair A, Griggs S and Mackillop E (2018) Engaging students as co-producers: A critical reflection on the policy commission model. Politics 38(4): 514-530.

Crossley-Frolick K (2010) Beyond Model UN: Simulating Multi-Level, Multi-Actor Diplomacy Using the Millennium Development Goals. International Studies Perspectives 11: 184-201.

Ehrlander M and Boylan B (2017) The Model Arctic Council: Educating Postsecondary Students on Arctic Issues and Governance through Simulation. International Studies Perspectives, 1-19

Enterline A and Jepsen E (2009) Chinazambia and Boliviafranca: A Simulation of Domestic Politics and Foreign Policy. International Studies Perspectives 10: 49-59.

Frederking B (2005) Simulations and Student Learning. Journal of Political Science Education $1: 385-93$.

Giovanello S, Kirk J and Kromer M (2013) Student Perceptions of a Role-Playing Simulation in an Introductory International Relations Course. Journal of Political Science Education 9(2): 197-208.

Glasgow S (2014) Stimulating Learning by Simulating Politics: Teaching Simulation Design in the Undergraduate Context. International Studies Perspectives 15(4): 525-537.

Hatipoglu E, Muftuler-Bac M and Murphy T (2014) Simulation Games in Teaching International Relations: Insights from a Multi-Day, Multi- Stage, Multi-Issue Simulation on Cyprus. International Studies Perspectives 15(4): 394-406.

Holland J (2013) Video Use and the Student Learning Experience in Politics and International Relations. Politics 34(3): 263-274.

Holsti O (2000) Reflections on Teaching and Active Learning. In: Lantis J, Kuzma L and Boehrer J (eds) The New International Studies Classroom. Boulder: Lynne Rienner.

Kempston T and Nicholas T (2014) The Drama of International Relations: A South China Sea Simulation. International Studies Perspectives 15(4): 459-476.

Krathwohl D (2002) A revision of Bloom's taxonomy: an overview. Theory into Practice, 41 (4): 212-218

Lantis J (1998) Simulations and experiential learning in the international relations classroom. International Negotiation, 3(1): 39-57. 
Ryan M, Saunders C, Rainsford E, and Thompson E (2014) Improving Research Methods Teaching and Learning in Politics and International Relations: A 'Reality Show' Approach. Politics 34(1): 8597.

Naude B (2018) Beyond the Lecture Hall: Skills Building for Political Science Students from a Rural South African University. International Studies Perspectives, 19(3): 235-249.

Raymond C (2010) Do Role-Playing Simulations Generate Measurable and Meaningful Outcomes? A Simulation's Effect on Exam Scores and Teaching Evaluations. International Studies Perspectives 11(1): 51-60.

Ripley B, Carter N, and Grove A (2009) League of Our Own: Creating a Model United Nations Scrimmage Conference. Journal of Political Science Education 5(1): 55-70.

Shellman S and Turan K (2006) Do Simulations Enhance Student Learning? An Empirical Evaluation of an IR Simulation. Journal of Political Science Education, 2(1),19-32.

Taylor K (2013) Simulations Inside and Outside the IR Classroom: A Comparative Analysis. International Studies Perspectives 14(2): 134-149.

Winham G (2002) Simulation for Teaching and Analysis. In: Kremenyuk V. (ed) International Negotiation: Analysis, Approaches, Issues. San Francisco: Jossey-Bass

Youde J (2008) Crushing Their Dreams? Simulations and Student Idealism. International Studies Perspectives 9(3): 348-356. 